\title{
Vancomycin-lock therapy for prevention of catheter-related bloodstream infection in very low body weight infants
}

\author{
Hong Liang ${ }^{1}$, Lian Zhang ${ }^{1,2^{*}}$, Xiaoping Guo ${ }^{1}$ and Li Sun ${ }^{1}$
}

\begin{abstract}
Background: This study was to evaluate the effectiveness and safety of vancomycin- lock therapy for the prevention of catheter-related bloodstream infection (CRBSI) in very low body weight (VLBW) preterm infant patients.
\end{abstract}

Methods: One hundred and thirty-seven cases of VLBW preterm infants who retained peripherally inserted central catheters (PICCS) were retrospectively reviewed, including 68 treating with heparin plus vancomycin (vancomycinlock group) and 69 with heparin only (control group). The incidence of CRBSI, related pathogenic bacteria, adverse events during the treatment, complications, antibiotic exposure, PICC usage time, hospital stay, etc. were compared between the above two groups.

Results: The incidence rate of CRBSI in the vancomycin-lock group $(4.4 \%, 3 / 68)$ was significantly less than in the control group $(21.7 \%, 15 / 69, p=0.004)$. Total antibiotic exposure time during the whole observation period was significantly shorter in the group than in the control group (11.2 \pm 10.0 vs $23.6 \pm 16.1 \mathrm{~d} ; p<0.001)$. No hypoglycemia occurred during the locking, and the blood concentrations of vancomycin were not detectable.

Conclusions: Vancomycin-lock may effectively prevent CRBSI in Chinese VLBW preterm infants and reduce the exposure time of antibiotics, without causing obvious side complications.

Keywords: Preterm infants, Very low body weight, Catheter-related bloodstream infection, Vancomycin, Lock, Prevention

\section{Background}

Peripherally inserted central catheters (PICCs) are currently commonly used in neonatal intensive care units (NICUs), especially for the treatment of extremely preterm infants and very low birth weight (VLBW) infants. However, usage of PICCs increases the risk of nosocomial infection, documented as catheter-related bloodstream infection (CRBSI) [1-3], which results in extended hospital stay and various life-threatening

\footnotetext{
* Correspondence: zhlian2015@163.com

'Department of Neonatology, Guangzhou Women and Children's Medical Center, Guangzhou 510623, P.R. China

${ }^{2}$ Department of Neonatology, Shenzhen Bao'an Maternal and Child Health Hospital, Shenzhen 518133, P.R. China
}

complications such as necrotizing enterocolitis (NEC), intraventricular hemorrhage (IVH), bronchopulmonary dysplasia (BPD) and retinopathy of prematurity (ROP), leading to a mortality rate of $4-29 \%[4,5]$. It is vital important to take preventive measures to reduce the incidence of CRBSI. In 2012, a bundle intervention strategy was recommended by the United States Center for Disease Control [6], which showed some efficacy in both adult and pediatric patients [7-9]. However, this strategy has limitations in the treatment for neonate patients, and CRBSI still remains a major and persistent problem in NICU of China's major medical centers $[10,11]$.

(c) The Author(s). 2021 Open Access This article is licensed under a Creative Commons Attribution 4.0 International License, which permits use, sharing, adaptation, distribution and reproduction in any medium or format, as long as you give appropriate credit to the original author(s) and the source, provide a link to the Creative Commons licence, and indicate if changes were made. The images or other third party material in this article are included in the article's Creative Commons licence, unless indicated otherwise in a credit line to the material. If material is not included in the article's Creative Commons licence and your intended use is not permitted by statutory regulation or exceeds the permitted use, you will need to obtain permission directly from the copyright holder. To view a copy of this licence, visit http://creativecommons.org/licenses/by/4.0/ The Creative Commons Public Domain Dedication waiver (http://creativecommons.org/publicdomain/zero/1.0/) applies to the data made available in this article, unless otherwise stated in a credit line to the data. 
The pathogenic microorganisms colonized inside catheters can easily form a bacterial biofilm and eventually spread with blood flow [12], which causes CRBSI. Antibiotic-lock therapy (ALT) has been developed that high-dose antibiotic solution dripped and maintained in the catheter cavity for a certain period can dissolve the biofilm formed on the wall to reduce the colonization of the bacteria and kill the embedded bacteria. Viale et al. demonstrated that most (93.3\%) patients carrying central line, who received antibiotic locks alone or locks plus systemic antibiotics therapy, successfully retained the central catheter, without the incidence of CRBSI and treatment-related adverse events [13]. A randomized trial showed that catheter locking by taurolidine significantly decreased the incidence rate of CBRSI in children with cancer compared with heparin [14]. Some other studies also reported the benefits from the application of ALT in the prevention of CRBSI [15-17]. However, Megged et al. showed combination of ALT with systemic antibiotics just achieved limited preventive effect on the central venous CRBSI in children [18].

Until now, ALT for neonate patients has been rarely reported $[19,20]$, and there have no related studies in relation to Chinese preterm infant patients yet. This study was to evaluate the effectiveness and safety of ALT in the treatment of VLBW preterm neonate patients at the NICU of Guangzhou Women and Children's Medical Center (Guangzhou, China).

\section{Methods}

\section{Patients}

Patients who were admitted to the NICU of Guangzhou Women and Children's Medical Center between March 2014 and December 2016 were retrospectively reviewed. Inclusion criteria of preterm infants were: 1) patients' birth weight $\leq 1.8 \mathrm{~kg}$, and required total or partial parenteral nutrition (TPN or PPN), 2) patients received routine retention of PICC line for more than 2 weeks, and 3) patients were not systemically administrated antibiotics during the catheter lock. Patients who: 1) had birth weight $>1.8 \mathrm{~kg}, 2$ ) died during the first week after birth or died of non-CRBSI reasons, 3 ) received routine retention of PICC line for less than 2 weeks, 4) were administrated with antibiotics before the catheter lock, 5) required umbilical venous catheters (UVCs), 6) were transferred to other hospitals or departments or failed to complete a clinical observation for at least 2 weeks, or 7 ) with congenital immunodeficiency, multiple malformations or congenital hypoglycemia, were excluded. The study was approved by the Ethics Committee of Guangzhou Women and Children's Medical Center (No. 2013-32). Written informed consent was obtained from each infant's guardians.

\section{Treatment}

Patients received treatment of heparin plus vancomycin (vancomycin-lock group) or heparin only (control group).

Before the lock of PICC catheter, clinicians' hands and catheter interface were strictly disinfected, and the lock solution was prepared by a qualified staff. Lock was carried out since the first day after the placement of PICC catheter, 3 times daily (q8h). PICC catheter position, redness and swelling, secretion, phlebitis, and obstruction were regularly recorded in a unified and strict way by an independent PICC management team at the NICU according to the centralized management and standard process [6].

In the vancomycin-lock group, $0.5 \mathrm{~mL}$ lock solution of $10 \mathrm{IU} / \mathrm{mL}$ heparin and $25 \mu \mathrm{g} / \mathrm{mL}$ vancomycin was given. If the disease status required systemic antibiotic treatment, vancomycin-lock was stopped, and only heparin solution would be used instead (q12h).

For each lock, the lock solution was retained for 30 min and was then discarded and flushed away from the catheter with $2 \mathrm{ml}$ of normal saline, followed by addition of the former solution used in the catheter. The lock procedure was carried out 3 times daily (q8h). Blood glucose was measured before and after the lock. Blood samples from the inner PICC catheters and peripheral veins were cultured in a BACT/ALERT 3D automatic blood bacteria culture system (BioMerieux, France). Positive blood samples showing bacteria growth were transferred to blood plates and chocolate plates, and were then cultured in a carbon dioxide incubator at $37^{\circ} \mathrm{C}$ for $24 \mathrm{~h}$. The bacteria species were then further identified using a VITEK 2 COMPACT automatic microbial identification and susceptibility system (BioMerieux) and a VITEK MS automatic rapid microbial mass spectrometry detection system (BioMerieux). Cultures that had not been detected bacteria growth for 5 days were considered negative blood culture.

The blood concentrations of vancomycin were measured every 2 weeks. Infection indicators were regularly monitored; once clinical symptoms were observed or infection indicators were elevated, blood from the peripheral vein and inner PICC catheter was cultured immediately. If PICC catheter needed to be removed, the catheter tip was cultured to identify the causative bacteria. At the end of the study, the catheter tip was cultured and the blood vancomycin concentrations were measured.

In the control group, only $0.5 \mathrm{~mL} 10 \mathrm{IU} / \mathrm{mL}$ heparin was used, and most of the other procedures were similar to those in the vancomycin-lock group.

Patients were not administrated with antibiotics before the catheter lock. However, during the treatment if the patients' symptoms became worse and they were 
suspected with sepsis, the physicians empirically used antibiotics (such as sulperazone, tienam/mepem, and vancomycin) until a line of indicators excluded the occurrence of sepsis.

During the study period there was no consensus on the selection of heparin- or vancomycin-lock strategy in our center, and physicians themselves decided to choose heparin- or vancomycin-lock. In addition, there was no obvious turning point about the strategy of PICC lock (such as switching from heparin- to vancomycin-lock), although since the late-stage of this study the number of patients received vancomycin-lock increased.

\section{Measurement}

The incidence and onset time of CRBSI were recorded. The pathogenic microorganisms from blood were cultured and identified, and the usage of antibiotics was recorded. The side effects of ALT, such as allergy to vancomycin, influence on body function, incidence of hypoglycemia, PICC fracture, embolism and slippage, and local port abscess during the lock, were observed.

\section{Definition}

CRBSI was determined according to the definition of CRBSI by the United States Center for Disease Control in 2012 [6].

Confirmed CRBSI was determined if: 1) infants exhibited symptoms of sepsis, 2) blood cultures from both the peripheral veins and catheters were identified same types of bacteria, and the catheter blood culture had a positive result $2 \mathrm{~h}$ earlier; or the culture of the catheter tip was positive and had the same types of bacteria as the peripheral blood culture, 3) other sources of infection were excluded.

Suspected CRBSI was determined if: 1) there was clinical symptoms of sepsis, 2) peripheral blood culture was positive but without consistent types of the identified bacteria with those from the inner catheter blood or catheter tip, or the culture of the peripheral blood was identified common skin symbionts, such as Staphylococcus epidermidis, coagulase-negative Staphylococcus, Bacillus and Candida, 3) bloodstream infection at other lesions were excluded, and antibiotic treatment was needed and clinical symptoms disappeared thereafter.

Suspected infection was defined if there was manifestation of clinical infection or the indicators of inflammation and infection, such as white blood cells (WBC), C-reactive protein (CRP) and procalcitonin, were abnormal, while the culture of blood or catheter tip was negative.

Colonization was defined if the catheter tip culture was positive after the observation, but there were no clinical symptoms in patients and the blood culture was negative. Non-catheter-related infection (i.e. non-CRBSI neonatal sepsis) was mainly determined based on at least 3 of the following criteria [21, 22]: 1) having clinical symptoms of sepsis, such as respiratory distress, apnea, hyperglycemia, hypoglycemia, vomiting and feeding intolerance, 2) blood cultures from within and outside catheters and those from the catheter tips were negative, 3) abnormal laboratory parameters, such as CRP concentration $>10 \mathrm{mg} / \mathrm{L}$ and $\left.\mathrm{WBC}<5^{*} 10^{9} / \mathrm{L}, 4\right)$ incidence of high risk factors for infection, such as group B Streptococcus positive in mothers, chorioamnionitis and premature rupture of membranes (PROM) for over $18 \mathrm{~h}$, and 5) antibiotic treatment was needed, and symptoms disappeared after that.

Infection rate per 1000 catheter-days was defined as the number of the infected cases/ total catheter-days $\mathrm{X}$ $1000 \%$. During the treatment if patients needed to be systematically administrated with antibiotics, the systematic administration time of antibiotics was determined as the time (day) of intravenous injection of antibiotics, such as sulperazone, tienam/mepem, and vancomycin, during the whole hospital stay.

\section{Data collection and statistical analysis}

Infants' basic physiological characteristics (such as gestational age, weight, APGAR score, mechanical ventilation [MV] time), suspected infection, major comorbidity (such as neonatal respiratory distress syndrome [NRDS], patent ductus arteriosus [PDA], and non-catheterrelated infection), major complications (such as intracranial infection, intracranial hemorrhage, NEC), death, and all adverse events (including local redness and swelling, PICC embolism, rupture and slipping, allergy, adverse drug reactions, and hypoglycemia) during the usage of PICC were collected. The incidence of CRBSI, identified types of pathogenic microorganisms, usage of antibiotics, parenteral nutrition time, PICC time, hospital stay, and hospitalization expenses were also collected.

Data were expressed as mean \pm standard derivation or median \pm interquartile range. All the above data were analyzed by a qualified statistician who did not participate in this work and was blinded to the grouping situation using SPSS 23 statistical software (SPSS Inc., Chicago, Illinois, USA). Measurement data were compared between the vancomycin-lock and control groups using $t$ test. Enumeration data were compared between groups using Pearson Chi-square test or Fisher's exact test. CRBSI risk ratios (RR) and 95\% confidence intervals (CIs) were assessed by COX statistical analysis. Probability of non-CRBSI was evaluated by Kaplan-Meier curve analysis. Comparisons with $p<0.05$ (two-tailed) were thought to be statistically significant.

\section{Results}

Two thousand two hundred and seventy-six cases of admitted preterm infant patients were preliminarily reviewed. After exclusion of 1836 cases with birth 
weight $>1.8 \mathrm{~kg}, 20$ dead during the first week after birth, 27 dead for severe complications, 12 transferred to other hospitals, 114 requiring UVCs, and 84 requiring neither UVC nor PICC, 183 infant patients were further reviewed, including 90 receiving vancomycin-lock (vancomycin-lock group) and 93 receiving heparin only (control group). After another exclusion of cases with PICC duration $<14$ d, those administrated with antibiotics during the catheter lock, and those dead or transferred to other departments, 137 cases were eventually analyzed, 68 in the vancomycinlock group and 69 in the control group (Fig. 1). It appeared that eventually the numbers of subjects in the vancomycin- and heparin-lock groups were similar, while as a retrospective study, the cases were not randomized to the two groups. Before the exclusion, the numbers of included subjects in the two groups were different although the difference was not too big.

There was no significant difference in gender, gestational age, birth weight, severe comorbidities (including neonatal sepsis, NRDS, NEC, PDA, and IVH above level II), PROM time, MV time, PICC days, TPN or PPN days, hospital stay, and hospitalization costs between the two groups (Table 1). This indicated that the basic information between the two groups were balanced and the comparison between the heparin- and vancomycin-lock related results was meaningful.

\section{Vancomycin-lock significantly reduced the incidence of CRBSI}

As shown in Table 2, the percentage of the total CRBSI cases (including the confirmed and suspected cases) in the vancomycin-lock group (4.4\%, 3 of 68) was significantly less than in the control group $(21.7 \%, 15$ of 69 , RR $0.20,95 \%$ CI $0.06-0.67, p=0.004)$. Particularly, the percentage of the confirmed CRBSI cases was significantly less in the vancomycin-lock group (4.4\%, 3 of 68 vs $15.9 \%, 11$ of 69 ; RR $0.28,95 \%$ CI $0.08-0.95, p=$ 0.045). The infection rate per 1000 catheter-days was significantly lower in the vancomycin-lock group $(1.34 \%$ o in the vancomycin-lock group vs $6.66 \%$ in the control group, RR 0.23, 95\% CI 0.07-0.80, $p=0.021$ ).

Finally, PICC catheter tip culture for bacteria was carried out in the two groups. Bacteria colonization was found in one case of the control group while it was not found in the vancomycin-lock group.

Kaplan-Meier survival curve analysis with an observation period of up to 40 days showed that in the same observational time point (i.e. day 10, 20,30, and 40), the number of patients without CRBSI in the vancomycinlock group was significantly larger than in the control group (all $p<0.001$, Fig. 2), indicating a higher probability of non-CRBSI in the vancomycin-lock group. This suggests that vancomycin-lock is beneficial to decrease the incidence of CRBSI and retain the PICC catheters for treatment in NICU.

We then further analyzed the pathogenic bacteria of CRBSI. Table 3 showed 18 patients were infected with pathogenic bacteria, including 12 with Gram-positive bacteria and 6 with Gram-negative bacteria. The Grampositive bacteria were the major pathogenic microorganisms of CRBSI (66.7\%, 12 of 18 cases). In the

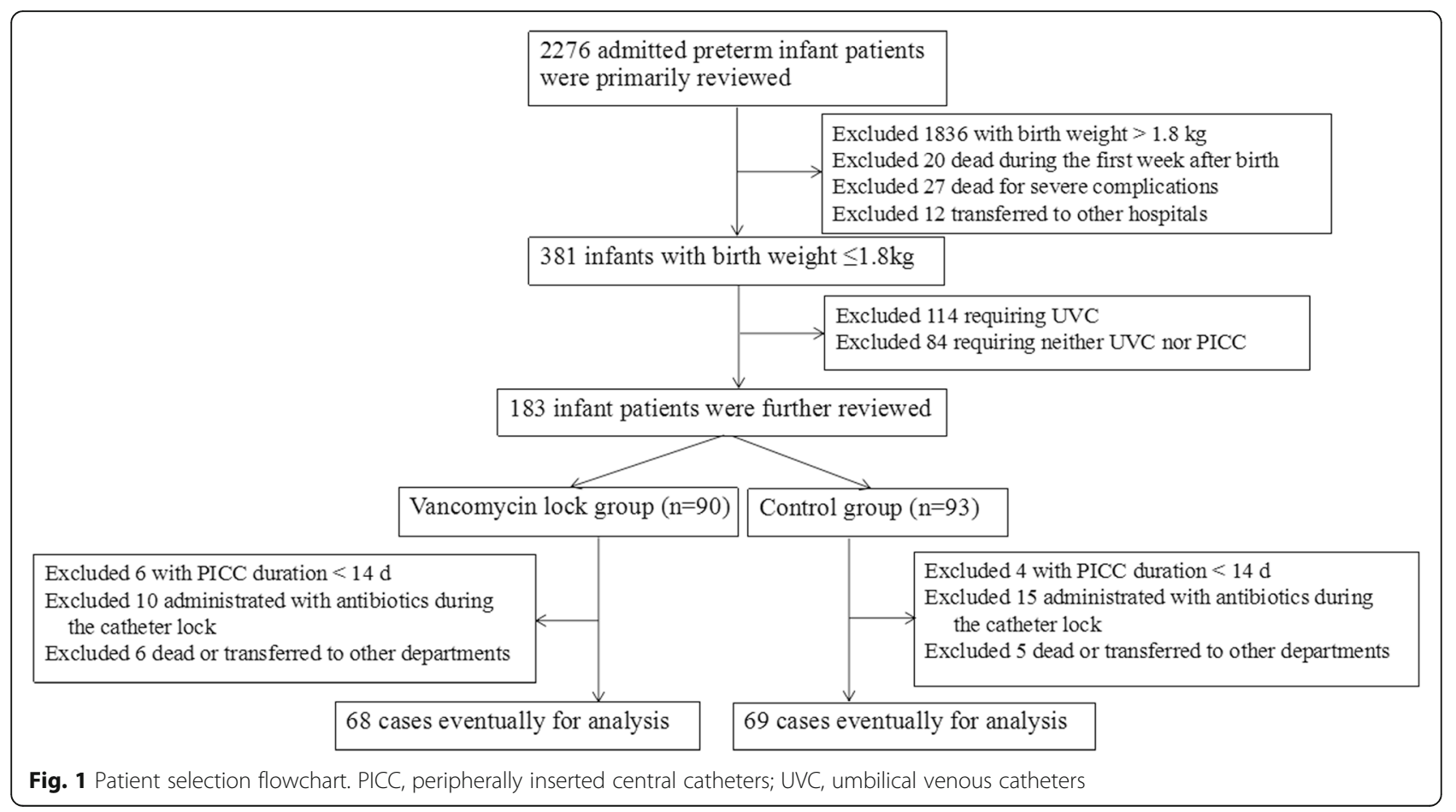


Table 1 Basic characteristics of infant patients

\begin{tabular}{llll}
\hline & Vancomycin-lock group $(\boldsymbol{n}=\mathbf{6 8})$ & Control group $(\boldsymbol{n}=\mathbf{6 9})$ & $\boldsymbol{p}$ value \\
\hline Gender (male, n (\%)) & $42(61.8)$ & $34(49.3)$ & $0.170^{*}$ \\
Gestational age, Wk & $29.8 \pm 1.90$ & $30.1 \pm 2.33$ & 0.323 \\
Birth weight, Kg & $1.2 \pm 0.19$ & $1.3 \pm 0.23$ & 0.765 \\
5-min APGAR score & $8.29 \pm 1.04$ & $8.7 \pm 0.71$ & 0.010 \\
Comorbilities & & & \\
Neonatal sepsis, n (\%) & $43(63.2)$ & $42(60.9)$ & $0.861^{*}$ \\
NRDS, n (\%) & $46(67.6)$ & $44(63.8)$ & $0.720^{*}$ \\
PDA, n (\%) & $30(44.1)$ & $31(44.9)$ & $1.000^{*}$ \\
IVH, n (\%) & $11(16.2)$ & $16(23.2)$ & $7(10.1)$ \\
NEC, n (\%) & $6(8.8)$ & $15(21.7)$ & $1.000^{*}$ \\
Meningitis, n (\%) & $4(5.9)$ & $45.3 \pm 92.9$ & $0.012^{*}$ \\
PROM time, h & $40.2 \pm 114$ & $17.0 \pm 17.9$ & 0.776 \\
MV time, d & $12.8 \pm 13.1$ & $33.7 \pm 19.6$ & 0.115 \\
PICC time, d & $33.0 \pm 12.7$ & $33.9 \pm 17.8$ & 0.798 \\
TPN or PPN time, d & $35.2 \pm 15.7$ & $51.8 \pm 28.2$ & $118,000 \pm 80,000$ \\
Hospital stay, d & $48.3 \pm 16.6$ & $110,000 \pm 53,000$ & 0.660 \\
Hospitalization costs, RMB (Yuan) & & 0.376 \\
\hline Note *showed & 0.491 \\
\hline
\end{tabular}

Note: *showed chi-square test, and other analysis was t-test; NRDS neonatal respiratory distress syndrome, PDA patent ductus arteriosus, IVH intraventricular hemorrhage, NEC necrotizing enterocolitis, PROM premature rupture of membrane, MV mechanical ventilation, PICC peripherally inserted central catheters, TPN total parenteral nutrition, $P P N$ part parenteral nutrition

vancomycin-lock group, only 1 case was infected with Gram-positive bacteria (i.e. S. aureus), while in the control group, 11 cases were infected with Gram-positive bacteria, including 2 cases of S. aureus, 2 of Enterococcus faecalis (including 1 confirmed and 1 suspected cases), 3 of S. epidermidis, and 4 of coagulase-negative Staphylococcus (including 1 confirmed and 3 suspected cases) (Table 3). The infection rate of Gram-positive bacteria was significantly less in the vancomycin-lock group than in the control group $(6 \%, 1 / 18$, vs $61 \%, 11 / 18 ; p=0.004$, Table 3). However, there was no significant difference in the infection rate of Gram-negative bacteria between the two groups $(11 \%, 2 / 18$ in the vancomycin-lock group vs $22 \%, 4 / 18$ in the control group; $p=0.681$ ).

\section{Vancomycin-lock significantly reduced the antibiotic exposure}

Generally, in the vancomycin-lock group the systematic administration time of antibiotics was significantly shorter than in the control group $(11.2 \pm 10.0$ vs $23.6 \pm$ $16.1 \mathrm{~d}, p<0.001$, Table 4). For patients with CRBSI, there was no significant difference in the antibiotic treatment time between the vancomycin-lock and control groups $(32.7 \pm 8.1$ vs $31.5 \pm 18.0 \mathrm{~d}, p=0.913)$. However, for patients without CRBSI, including those with noncatheter-related infection or suspected infection, the antibiotic treatment time was significantly shorter in the vancomycin-lock group than in the control group $(10.2 \pm 9.0$ vs $21.4 \pm 11.0 \mathrm{~d}, p<0.001$, Table 4$)$. Therefore, low-dose vancomycin-lock decreases the exposure time of antibiotics in infant patients.

During the catheter locking period, there were no serious adverse events (such as PICC fracture, slippage and embolism, and local suppuration in the PICC port), no events of allergy to vancomycin, and no incidence of hypoglycemia $(<40 \mathrm{mg} / \mathrm{ml})$. In addition, the serum concentrations of vancomycin both at 2 weeks after the start of catheter lock and at the completion of lock were lower than the minimal detection concentration in plasma $(<3 \mu \mathrm{g} / \mathrm{ml})$. Therefore, vancomycin-lock did not cause severe adverse events and antibiotic residue.

Table 2 Incidence of CRBSI in the vancomycin-lock and control groups

\begin{tabular}{lllll}
\hline & Vancomycin-lock group $(\boldsymbol{n}=\mathbf{6 8})$ & Control group $(\boldsymbol{n}=\mathbf{6 9 )}$ & RR $(\mathbf{9 5 \%} \% \mathbf{C l})$ & $\boldsymbol{p}$ value \\
\hline CRBSI n (\%) & $3(4.4 \%)$ & $15(21.7 \%)$ & $0.20(0.06-0.67)$ & 0.004 \\
Confirmed n (\%) & $3(4.4 \%)$ & $11(15.9 \%)$ & $0.28(0.08-0.95)$ & 0.045 \\
Suspected n (\%) & 0 & $4(5.8 \%)$ & $0.11(0.01-2.05)$ & 0.120 \\
\hline
\end{tabular}

Note: CBRSI included the confirmed and suspected cases 


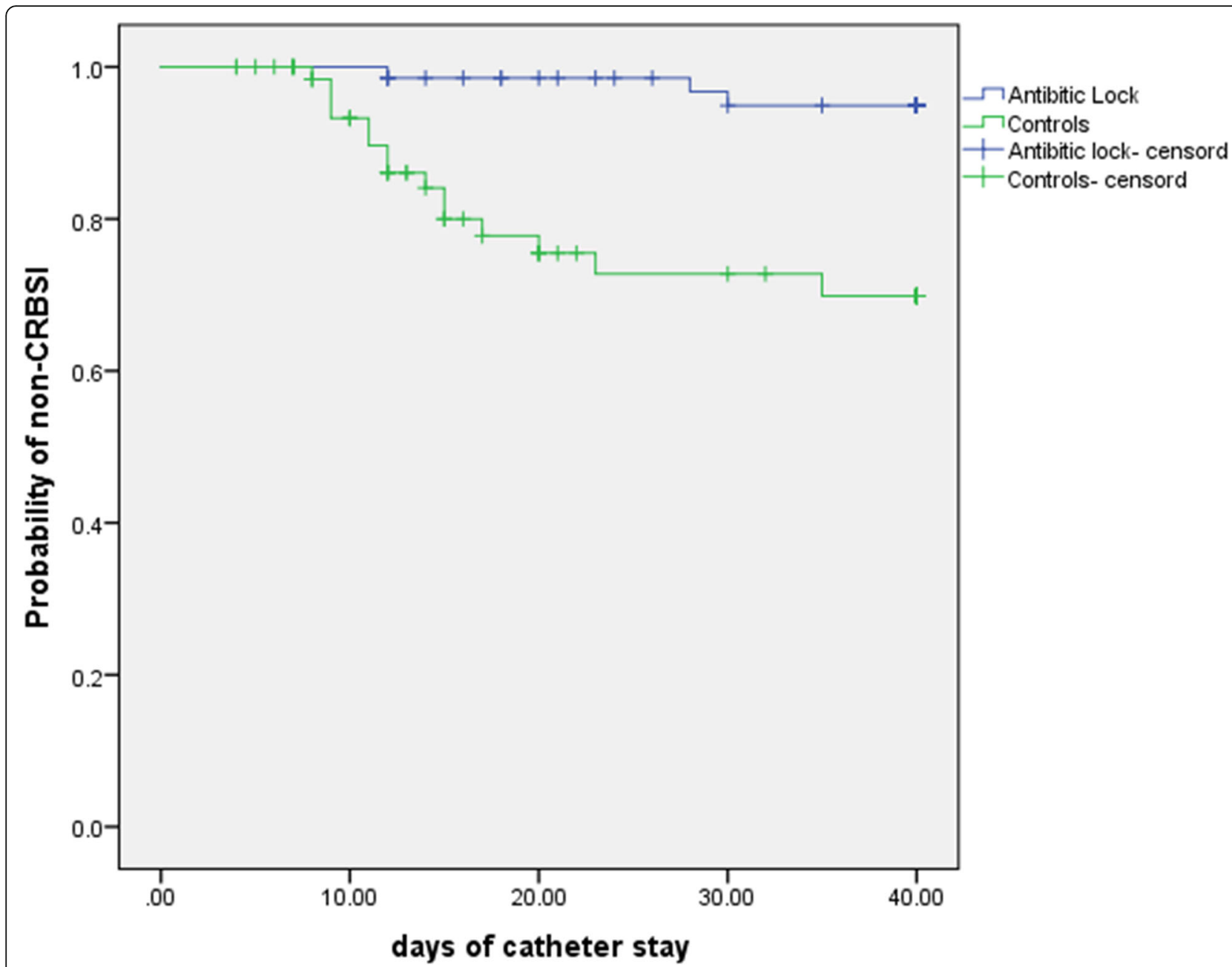

Fig. 2 Kaplan-Meier survival curve analysis of the probability of non-CRBSI in the vancomycin-lock and control groups. The probability (log rank (mantel-cox)) of non-CRBSI was significantly larger in the vancomycin-lock group at each same time point after the baseline (i.e. day 10, 20,30, and 40) $(p<0.001)$. The numbers of patients without CRBSI in the vancomycin-lock and control groups were 68 vs 69 at day 0,67 vs 54 at day 10,59 vs 33 at day 20,53 vs 26 at day 30, and 50 vs 23 at day 40, respectively

\section{Discussion}

The commonly used central venous catheterization may lead to CRBSI, a major and persistent problem in NICU of China [10, 11]. ALT has been successfully employed to prevent CRBSI in adults and children patients [15-17, 23-25], while it has rarely been carried out in neonates $[19,20]$. In the present study, we evaluated the efficacy of vancomycin-lock technique in the treatment of VLBW preterm infants who needed long-term retention of PICC catheters in NICU. We showed that the CRBSI incidence rate was significantly decreased in the vancomycin-lock group compared with that in the control group, indicating the preventive role of vancomycinlock in CRBSI. This study could be clinically used to prevent the incidence of CRBSI during the catheterretaining process in VLBW infants. Until now, there have no similar results in terms of Chinese VLBW preterm infant patients in NICU yet. This study will be beneficial to the application of ALT for VLBW preterm infant patients in not only Chinese populations but also others.

We showed that Gram-positive bacteria were the major pathogenic microorganisms in CRBSI (66.7\%). The Gram-positive coccus are the major types of pathogens in bacteria biofilms [26, 27]. Vancomycin has an inhibitory effect on a variety of gram-positive cocci, particularly bacteria in the inner catheter bacteria biofilm $[28,29]$, and its efficacy and safety in neonates has been confirmed [30, 31]. Therefore, vancomycin was selected for antibiotic-lock so as to prevent the incidence of CRBSI, which is consistent with some reports using vancomycin as the main locking antibiotic [23, 32, 33].

We showed that ALT did effectively reduce the incidence of CRBSI, without obviously causing systemic side 
Table 3 CRBSI bacteria in the vancomycin-lock and control groups

\begin{tabular}{|c|c|c|c|}
\hline & Vancomycin-lock group & Control group & $p$ value \\
\hline Gram positive (n/\%) & $1(1 / 18,6 \%)$ & $11(11 / 18,61 \%)$ & 0.004 \\
\hline S. aureus & 1 & 2 & \\
\hline Enterococcus & & 2 & \\
\hline S. epidermidis & & 3 & \\
\hline Coagulase negative Staphylococcus & & 4 & \\
\hline Gram negative (n/\%) & $2(2 / 18,11 \%)$ & $4(4 / 18,22 \%)$ & 0.681 \\
\hline Klebsiella & 1 & 2 & \\
\hline E. coli & 1 & & \\
\hline \multicolumn{4}{|l|}{ Pseudomonas aeruginosa } \\
\hline \multicolumn{4}{|l|}{ Serratia } \\
\hline E. intestinal & & 1 & \\
\hline Siamese line well bacteria & & 1 & \\
\hline \multicolumn{4}{|l|}{ Candida } \\
\hline Total & 3 & 15 & \\
\hline
\end{tabular}

effects, which is consistent with Garland et al.' and Filippi.' results $[19,20]$ (Table 5). Interestingly, our result showed a lower infection rate per 1000 catheterdays (1.34\%) in infants receiving ALT when compared with these two studies (2.3\%o and $6.6 \%$, respectively) $[19,20]$. This suggests better efficacy of using ALT to prevent CBRSI in preterm infant patients in our study.

Although ALT could successfully prevent the incidence of CRBSI, we did not observe significant improvement of treatment outcomes such as MV time, PICC days, TPN or PPN days, and hospital stay. Similarly, in a multicentered (14 NICU centers) prospective study Ruth et al. demonstrated that the outcomes were not obviously improved with the reduction of CRBSI rate [34]. Our and Ruth et al.'s results indicate that contribution of ALT to reduce the incidence of CRBSI is independent of improving the treatment outcomes, which might be related to difference in the types and severity of the diseases in infants.

It is necessary to evaluate the side effects of vancomycin on body. In our study, the blood concentrations of vancomycin were measured every 2 weeks. We showed that all the blood vancomycin concentrations were $<3 \mu \mathrm{g} / \mathrm{ml}$ (lower than the minimum detectable limit). This may be due to that limited vancomycin was locally locked in PICCs during ALT. Given the total administrated dose of vancomycin (3 times) in the catheter was only $75 \mu \mathrm{g}$ per day and it was eliminated so completely (even undetectable), it would not accumulate in body to bring about side effects.

We demonstrated that vancomycin-lock significantly reduced the antibiotic exposure time during the catheter retaining, which had been rarely reported. Filippi et al. used amoxicillin or gentamicin in all neonate patients for 10 days, fluconazole for within 1 month and sodium fusidate for catheter-locking, and found that the systematic antibiotic exposure time was not obviously reduced with the significant decrease of total CRBSI incidence [20]. In contrast, our ALT procedure appears better. We showed that antibiotic exposure time was generally significantly shorter in patients, particularly in patients with non-CRBSI (regardless of non-catheter-related infection or suspected infection), in the vancomycin-lock group than in the control group. This suggests that due to effectively preventing CRBSI, the local vancomycin-lock in PICCs reduces the requirement of the systematic antibiotic exposure in infant patients, which may decrease the accumulation of antibiotics in body and thus avoid the antibiotic-related side effects. Interestingly, for CRBSI patients, the antibiotic exposure time was

Table 4 Treatment time of systematic administration of antibiotics

\begin{tabular}{llll}
\hline & Vancomycin-lock group $(\boldsymbol{n}=\mathbf{6 8})$ & Control group $(\boldsymbol{n}=\mathbf{6 9 )}$ & $\boldsymbol{p}$ value \\
\hline Antibiotics covered, d & $11.2 \pm 10.0$ & $23.6 \pm 16.1$ & $<0.001$ \\
CRBSI patients, d & $32.7 \pm 8.1$ & $31.5 \pm 18.0$ & 0.913 \\
Non-CRBSI patients, d & $10.2 \pm 9.0$ & $21.4 \pm 11.0$ & $<0.001$ \\
Non-catheter-related infection patients, d & $17.0 \pm 7.0$ & $28.8 \pm 14.2$ & 0.001 \\
Suspected infection patients, d & $7.6 \pm 8.3$ & $15.2 \pm 12.8$ & 0.008 \\
\hline
\end{tabular}


Table 5 Comparison of the present study with Galand et al.' and Filippi et al.' results

\begin{tabular}{llll}
\hline & $\begin{array}{l}\text { Galand et al.' study } \\
\text { (Prospective, RCT) }\end{array}$ & $\begin{array}{l}\text { Filippi et al.' study } \\
\text { (Prospective, RCT) }\end{array}$ & $\begin{array}{l}\text { Present study } \\
\text { (Retrospective study) }\end{array}$ \\
\hline Gestational age, Wk & $27 \pm 3.8$ & $29 \pm 4.8$ & $30 \pm 1.9$ \\
Birth weight, Kg & $1.1 \pm 0.72$ & $1.0 \pm 0.61$ & $1.3 \pm 0.18$ \\
PICC time, d & $20.3 \pm 11.4$ & $7.5(2-29)$ & $33.0 \pm 12.7$ \\
CRBSI in AL (n/\%) & $4.8 \%(2 / 42)$ & $6.0 \%(3 / 50)$ & $4.4 \%(3 / 68)$ \\
CRBSI in C (n/\%) & $30.2 \%(13 / 43)$ & $24.5 \%(13 / 53)$ & $21.7 \%(15 / 69)$ \\
P value & 0.002 & $<0.01$ & 0.004
\end{tabular}

$R C T$ randomized controlled trial, $A L$ antibiotic-lock group, $C$ control treatment without antibiotic-lock. $P$ value showed the comparison between the incidence rate of CRBSI in AL and C groups

insignificantly shorter in the vancomycin-lock group than in the heparin-lock group, while for non-CRBSI patients, the antibiotic exposure time was significantly shorter in the vancomycin-lock group. This may be related to the difference in the response to vancomycinlock between CRBSI and non-CRBSI patients. The response of non-catheter-related infection (a type of nonCRBSI) to vancomycin-lock appeared to be more sensitive than that of CRBSI, as a result, significantly shorter antibiotic exposure time in the vancomycin-lock vs heparin-lock group was observed in non-catheter-related infection patients when compared with CRBSI patients. For suspected infection (another type of non-CRBSI), antibiotic exposure time was also significantly shorter in the vancomycin-lock vs heparin-lock group, which might be due to that physicians using vancomycin-lock would be more confident to stop the empirical antibiotics usage in time while those using heparin-lock would be more conservative to ensure adequate antibiotics usage. This result needs to be further validated by prospectively randomized controlled studies with larger sample size.

Hypoglycemia is a most concerned side effect during the ALT procedure. The subjects of this study were VLBW preterm infants and they needed continuous infusion of high energy nutrient solution before they could establish intestinal nutrition. During the lock process, we needed to stop the infusion of nutrient solution for $30 \mathrm{~min}$. To prevent the incidence of hypoglycemia, we measured the blood glucose before locking. If the blood glucose concentrations were too low $(<50 \mathrm{mg} / \mathrm{dL})$, the vancomycin-lock procedure was be postponed. Therefore, there were no hypoglycemic events observed.

In our study, vancomycin was used as the locking drug, with strong pertinence and small resistance. Vancomycin-lock could obviously reduce the bloodstream infection of Gram-positive cocci but failed to control that of Gram-negative bacilli. This might be related to its nature as a limited-spectrum antibiotic. Gram-negative bacteria-induced CRBSI may involve a more complex pathogenesis and prevention strategy [35]. Daptomycin has been recently recommended for its strong penetration [33, 36, 37]. Next, vancomycin will be combined with daptomycin or other antibiotics to be used as lock solution for preterm infant patients to achieve better outcomes.

There are several limitations in this study. This was a retrospective study that there might be bias in the selection of cases, due to that subjects were not randomly allocated to receive heparin- or vancomycin-lock, and incompletion of clinical information. In addition, the sample size of this study was not large. A prospectively, multicentered, randomized, controlled, and doubleblinded trials with more preterm infant patients are warranted to validate this result.

\section{Conclusion}

ALT with vancomycin is effective and safe in prevention of CRBSI during catheter retaining in Chinese VLBW preterm infant patients. Combination of ALT with other measures, such as bundle management, may further reduce the CRBSI.

\section{Abbreviations}

CRBSI: Catheter-related bloodstream infection; VLBW: Very low body weight; PICC: Peripherally inserted central catheter; NICU: Neonatal intensive care unit; NEC: Necrotizing enterocolitis; IVH: Intraventricular hemorrhage; BPD: Bronchopulmonary dysplasia; ROP: Retinopathy of prematurity; ALT: Antibiotic-lock therapy; TPN: Total parenteral nutrition; PPN: Partial parenteral nutrition; PROM: Premature rupture of membrane; MV: Mechanical ventilation; NRDS: Neonatal respiratory distress syndrome; PDA: Patent ductus arteriosus; WBC: White blood cells; CRP: C-reactive protein; RR: Risk ratios; Cl: Confidence intervals

\section{Acknowledgements}

Not Applicable.

\section{Authors' contributions}

$\mathrm{HL}$ designed and carried out this study and drafted the manuscript, LZ guided the study and manuscript drafting, XG collected the data and participated in treating the patients. LS supervised the monitoring of patients. All authors approved the final version of the manuscript.

\section{Funding}

This study was supported by the Guangdong Provincial Science and Technology Department Program (No. 20150110). The funding body played no role in the study design, data collection, analysis and interpretation, and manuscript writing. 


\section{Availability of data and materials}

The datasets generated during and/or analyzed during the current study are available from the corresponding author on reasonable request.

\section{Ethics approval and consent to participate}

The study was approved by the Ethics Committee of Guangzhou Women and Children's Medical Center (No. 2013-32). Written informed consent was obtained from each infant's guardians.

\section{Consent for publication}

Not applicable.

\section{Competing interests}

Not applicable.

Received: 14 June 2020 Accepted: 20 December 2020

Published online: 04 January 2021

\section{References}

1. Taylor JE, McDonald SJ, Tan K. A survey of central venous catheter practices in Australian and New Zealand tertiary neonatal units. Aust Crit Care. 2014; 27:36-42.

2. Soares BN, Pissarra S, Rouxinol-Dias AL, Costa S, Guimarães H. Complications of central lines in neonates admitted to a level III neonatal intensive care unit. J Matern Fetal Neonatal Med. 2018;31(20):2770-6.

3. Sannoh S, Clones B, Munoz J, Montecalvo M, Parvez B. A multimodal approach to central venous catheter hub care can decrease catheter-related bloodstream infection. Am J Infect Control. 2010;38(6):424-9.

4. Dudeck MA, Horan TC, Peterson KD, Allen-Bridson K, Morrell G, Pollock DA et al. National Healthcare Safety Network (NHSN) report, data summary for 2010, device-associated module. Am J Infect Control. 2011;39(10):798-816.

5. Lai NM, Taylor JE, Tan K, Choo YM, Ahmad Kamar A, Muhamad NA. Antimicrobial dressings for the prevention of catheter-related infections in newborn infants with central venous catheters. Cochrane Database Syst Rev. 2016;3:CD011082.

6. Miller DL, O'Grady NP, Society of Interventional Radiology. Guidelines for the prevention of intravascular catheter-related infections: recommendation relevant to interventional radiology for venous catheter placement and maintenance. J Vasc Interv Radiol. 2012;23(8):997-1007.

7. Hsin HT, Hsu MS, Shieh JS. The long-term effect of bundle care for catheterrelated blood stream infection: 5-year follow-up. Postgrad Med J. 2017; 93(1097):133-7.

8. Resende DS, Peppe AL, dos Reis H, Abdallah VO, Ribas RM, Gontijo Filho PP. Late onset sepsis in newborn babies: epidemiology and effect of a bundle to prevent central line associated bloodstream infections in the neonatal intensive care unit. Braz J Infect Dis. 2015;19(1):52-7.

9. Duffy EA, Rodgers CC, Shever LL, Hockenberry MJ. Implementing a daily maintenance care bundle to prevent central line-associated bloodstream infections in pediatric oncology patients. J Pediatr Oncol Nurs. 2015;32(6): 394-400.

10. Wen J, Yu Q, Chen H, Chen N, Huang S, Cai W. Peripherally inserted central venous catheter-associated complications exert negative effects on body weight gain in neonatal intensive care units. Asia Pac J Clin Nutr. 2017;26(1): $1-5$.

11. Yuan $Y$, Zhou W, Rong X, Lu WN, Zhang Z. Incidence and factors associated with nosocomial infections in a neonatal intensive care unit (NICU) of an urban children's hospital in China. Clin Exp Obstet Gynecol. 2015;42(5):61928.

12. Yousif A, Jamal MA, Raad I. Biofilm-based central line-associated bloodstream infections. Adv Exp Med Biol. 2015;830:157-79.

13. Viale $P$, Pagani $L$, Petrosillo $N$, Signorini $L$, Colombini $P$, Macri $G$, et al. Antibiotic lock-technique for the treatment of catheter-related bloodstream infections. J Chemother. 2003;15(2):152-6.

14. Handrup MM, Fuursted K, Funch P, Møller JK, Schrøder H. Biofilm formation in long-term central venous catheters in children with cancer: a randomized controlled open-labelled trial of taurolidine versus heparin. APMIS. 2012; 120(10):794-801.

15. Dümichen MJ, Seeger K, Lode HN, Kühl JS, Ebell W, Degenhardt P, et al. Randomized controlled trial of taurolidine citrate versus heparin as catheter lock solution in paediatric patients with haematological malignancies. J Hosp Infect. 2012;80(4):304-9.
16. Kim EY, Saunders P, Yousefzadeh N. Usefulness of anti-infective lock solutions for catheter-related bloodstream infections. Mt Sinai J Med. 2010; 77(5):549-58.

17. Silva TN, Mendes ML, Abrão JM, Caramori JT, Ponce D. Successful prevention of tunneled central catheter infection by antibiotic lock therapy using cefazolin and gentamicin. Int Urol Nephrol. 2013;45(5):1405-13.

18. Megged O, Shalit I, Yaniv I, Fisher S, Livni G, Levy I. Outcome of antibiotic lock technique for persistent central venous catheter-associated coagulasenegative Staphylococcus bacteremia in children. Eur J Clin Microbiol Infect Dis. 2010;29(2):157-61.

19. Garland JS, Alex CP, Henrickson KJ, MCAuliffe TL, Maki DG. A vancomycinheparin lock solution for prevention of nosocomial bloodstream infection in critically ill neonates with peripherally inserted central venous catheters: a prospective, randomized trial. Pediatrics. 2005;116(2):e198-205.

20. Filippi L, Pezzati M, Di Amario S, Poggi C, Pecile P. Fusidic acid and heparin lock solution for the prevention of catheter-related bloodstream infections in critically ill neonates: a retrospective study and a prospective, randomized trial. Pediatr Crit Care Med. 2007;8(6):556-62.

21. Polin RA, Committee on Fetus and Newborn. Management of neonates with suspected or proven early-onset bacterial sepsis. Pediatrics. 2012;129(5): 1006-15.

22. Stocker M, van Herk W, El Helou S, Dutta S, Fontana MS, Schuerman FABA, et al. Procalcitonin-guided decision making for duration of antibiotic therapy in neonates with suspected early-onset sepsis: a multicentre, randomised controlled trial (NeoPIns). Lancet. 2017;390(10097):871-81.

23. Snaterse M, Rüger W, Scholte Op Reimer WJ, Lucas C. Antibiotic-based catheter lock solutions for prevention of catheter-related bloodstream infection: a systematic review of randomised controlled trials. J Hosp Infect. 2010;75(1):1-11.

24. Sofroniadou S, Revela I, Smirloglou D, Makriniotou I, Zerbala S, Kouloubinis A, et al. Linezolid versus vancomycin antibiotic lock solution for the prevention of nontunneled catheter-related blood stream infections in hemodialysis patients: a prospective randomized study. Semin Dial. 2012; 25(3):344-50.

25. Moore CL, Besarab A, Ajluni M, Soi V, Peterson EL, Johnson LE, et al. Comparative effectiveness of two catheter locking solutions to reduce catheter-related bloodstream infection in hemodialysis patients. Clin J Am Soc Nephrol. 2014;9(7):1232-9.

26. Percival SL, Kite P. Intravascular catheters and biofilm control. J Vasc Access. 2007:8(2):69-80.

27. Bustos C, Aguinaga A, Carmona-Torre F, Del Pozo JL. Long-term catheterization: current approaches in the diagnosis and treatment of portrelated infections. Infect Drug Resist. 2014;7:25-35.

28. Fernández-Hidalgo N, Gavaldà J, Almirante B, Martín MT, Onrubia PL, Gomis $X$, et al. Evaluation of linezolid, vancomycin, gentamicin and ciprofloxacin in a rabbit model of antibiotic-lock technique for Staphylococcus aureus catheter-related infection. J Antimicrob Chemother. 2010;65(3):525-30.

29. Zhang Y, Fu Y, Yu J, Ai Q, Li J, Peng N, et al. Synergy of ambroxol with vancomycin in elimination of catheter-related Staphylococcus epidermidis biofilm in vitro and in vivo. J Infect Chemother. 2015;21(11):808-15.

30. Hammer BM, Lardieri AB, Morgan JA. Appropriate use of Vancomycin in NICU despite free-for-all policy. J Pediatr Pharmacol Ther. 2016;21(3):207-12.

31. Leroux S, Jacqz-Aigrain E, Biran V, Lopez E, Madeleneau D, Wallon C, et al. Clinical utility and safety of a model-based patient-tailored dose of Vancomycin in neonates. Antimicrob Agents Chemother. 2016;60(4):2039-42.

32. van de Wetering MD, van Woensel JB, Lawrie TA. Prophylactic antibiotics for preventing gram positive infections associated with long-term central venous catheters in oncology patients. Cochrane Database Syst Rev. 2013; 11:CD003295.

33. Fernández-Hidalgo N, Almirante B. Antibiotic-lock therapy: a clinical viewpoint. Expert Rev Anti-Infect Ther. 2014;12(1):117-29.

34. Gilbert RE, Mok Q, Dwan K, Harron K, Moitt T, Millar M, et al. Impregnated central venous catheters for prevention of bloodstream infection in children (the CATCH trial): a randomised controlled trial. Lancet. 2016;387(10029):1732-42.

35. Larson EL, Cimiotti JP, Haas J, Nesin M, Allen A, Della-Latta P, et al. Gramnegative bacilli associated with catheter-associated and non-catheterassociated bloodstream infections and hand carriage by healthcare workers in neonatal intensive care units. Pediatr Crit Care Med. 2005:6(4):457-61.

36. Del Pozo JL, Rodil R, Aguinaga A, Yuste JR, Bustos C, Montero A, et al. Daptomycin lock therapy for grampositive long-term catheter-related bloodstream infections. Int J Clin Pract. 2012;66(3):305-8. 
37. Yen HW, Yang WC, Tarng DC, Yang CY, Chuang CL, Huang LJ, et al. Daptomycin antibiotic lock therapy for hemodialysis patients with grampositive bloodstream infections following use of tunneled, cuffed hemodialysis catheters: retrospective single center analysis. Hemodial Int. 2016;20(2):315-20.

\section{Publisher's Note}

Springer Nature remains neutral with regard to jurisdictional claims in published maps and institutional affiliations.

Ready to submit your research? Choose BMC and benefit from:

- fast, convenient online submission

- thorough peer review by experienced researchers in your field

- rapid publication on acceptance

- support for research data, including large and complex data types

- gold Open Access which fosters wider collaboration and increased citations

- maximum visibility for your research: over $100 \mathrm{M}$ website views per year

At $\mathrm{BMC}$, research is always in progress.

Learn more biomedcentral.com/submissions 